\title{
General Health Status of Patients with Pemphigus Vulgaris
}

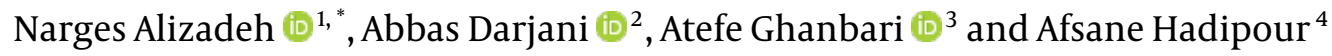 \\ ${ }^{1}$ Dermatology Department, Razi Hospital, Medical Faculty, Guilan University of Medical Sciences Rasht, Iran \\ ${ }^{2}$ Department of Dermatology, Medical Faculty, Guilan University of Medical Sciences, Rasht, Iran \\ ${ }^{3}$ Shahid Beheshti Nursing and Midwifery School, Guilan University of Medical Sciences, Rasht, Iran \\ ${ }^{4}$ Medical Faculty, Guilan University of Medical Sciences, Rasht, Iran \\ "Corresponding author: Dermatology Department, Razi Hospital, Medical Faculty, Guilan University of Medical Sciences Rasht, Iran. Tel: +98-1333690006, Fax: +98-1333690036, \\ Email: narges.alizadeh7@gmail.com
}

Received 2020 October 05; Revised 2021 July 18; Accepted 2021 July 26.

\begin{abstract}
Background: Pemphigus vulgaris is a severe autoimmune disease that involves skin and mucosal membranes by blistering lesions of varying sizes. Pemphigus is often associated with psychological stress.

Objectives: This study aimed to show the status of general health in patients suffering from this disease.

Methods: A descriptive study was conducted on 35 new cases of pemphigus vulgaris that were referred to the tertiary level hospital from March 2017 to March 2018. Personal and clinical data were gathered by interviewing. Assessment of severity of the disease was done by the Ikeda index, and GHQ-28 questionnaires were used to measure their general health status.

Results: A total of 35 new cases of non-treated pemphigus vulgaris (16 females and 19 males; mean age of 48.3 years, range 25 - 84 years) participated in this study. Median severity score of pemphigus was 4.1. Moreover, GHQ-28 positivity was detected in $65.7 \%$ o the patients. Social dysfunction and anxiety/insomnia had higher scores in subscales. There was a reverse relationship between disease severity and GHQ-28 values $(\mathrm{P}<0.05)$.

Conclusions: Pemphigus may negatively affect the general health of patients, and this issue should be considered in the treatment of this disease.
\end{abstract}

Keywords: Pemphigus Vulgaris, General Health Questionnaire (GHQ), Anxiety/Insomnia, Social Dysfunction, Depression

\section{Background}

Pemphigus vulgaris is a chronic autoimmune disorder that involves blistering and erosion of the skin and mucous membranes. In most cases, patients suffer from painful mouth lesions. These lesions have different sizes, irregularly shaped in gingival, buccal, or palatine with slow healing. Three primary subtypes of pemphigus include pemphigus vulgaris, pemphigus foliaceus, and paraneoplastic pemphigus. Pemphigus vulgaris accounts for approximately $70 \%$ of pemphigus cases (1).

Although skin diseases are rarely life-threatening, their impact on the quality of life and general health can be prominent. Recent studies have shown a strong link between the disease and the physical and mental condition of patients (2-8). On the other hand, psychological and emotional elements are affecting factors in improvement and response to the treatments in this autoimmune and dermatologic disease $(3,9,10)$. Indeed, psychiatric morbidities are important among patients with chronic skin diseases such as pemphigus.

General health status can be measured by different tools. Minor psychiatric disorders are defined by the General Health questionnaire (GHQ). GHQ-28 can also detect non-psychotic disorders such as anxiety, and insomnia, social dysfunction, and severe depression $(11,12)$.

It seems that differences between geographic area, cultural situation, and socioeconomic status in addition to severity and duration of the disease and treatment adherence may affect general health. There are no published studies on the impact of this disease on general health of patients in Iran.

\section{Objectives}

The aim of this study was to show the impact of pemphigus on general health status of patients in the north of Iran.

\section{Methods}

In this cross-sectional study, all new cases of pemphigus vulgaris who were referred to Razi Tertiary Level Hospital from March 2017 to March 2018 were observed. This

Copyright (c) 2021, Journal of Skin and Stem Cell. This is an open-access article distributed under the terms of the Creative Commons Attribution-NonCommercial 4.0 International License (http://creativecommons.org/licenses/by-nc/4.0/) which permits copy and redistribute the material just in noncommercial usages, provided the original work is properly cited. 
study was approved by the Research Committee of Guilan University of Medical Sciences as IR.GUMS.REC.1396.187.

Written informed consent was obtained from the patients. Personal and clinical data were gathered by interviewing a dermatologist. Assessment of severity of the disease was done by Ikeda index that is calculated based on four criteria (Nikolsky phenomenon, number of new blisters per day, affected area\%, oral lesions\%). Each item is scored from 0 to 3 . The total score gives the disease severity index: $<5$ mild, $5-7=$ moderate and $>7=$ severe (13).

The patients were given self-administered GHQ-28 questionnaires to measure general health status.

\subsection{The Likert Scoring Method}

used in this study with symptom severity scales 0 - 3 in 4 domains. These domains are somatic symptoms (items 1 - 7); anxiety/insomnia (items 8 - 14); social dysfunction (items 15 - 21), and severe depression (items 22 - 28). Each item is accompanied by four possible responses with a total possible score ranging from 0 to 84 . In every four subscales, a score of fewer than 7 represented negative or healthy status. Cut-off point for the presence of distress by this method is 23 , and higher scores indicate a higher chance of having mild psychiatric disorder (GHQ-28 positivity).13The reliability and validity of the Persian version of this questionnaire have been shown in recent studies (1416).

Statistical analyses were done by SPSS version 16 . Student T-test was used for comparing the mean values of continuous dichotomized variables, and bivariate analyses with chi-square test were used to determine the association of psychiatric morbidity with other variables. A Pvalue $<0.05$ was considered significant.

\section{Results}

Thirty-five new cases of pemphigus vulgaris (16 women and 19 men; mean age of 48.3 years, range 25 - 84 years) participated in this study, including 23 married, 2 single subjects, and the others were widow or divorced. Based on the extension of lesion to skin and mucosa, mucocutaneous involvement was seen in 25 patients, 6 patients had only cutaneous lesions, and the others had mucosal lesions. Disease duration before recruitment was from 1 month to 12 months, with a median duration of 4.5 months.

Median severity score was 4.1 (minimum 2, maximum $8)$. Mild severity score $(<5)$ was seen in 26 patients $(74.3 \%)$, moderate severity score $(5-7)$ in 8 patients, and severe severity score in only one patient (Table 1 ).

GHQ-28 positivity was detected in 23 patients (65.7\%). Social dysfunction and anxiety/insomnia had the higher

\begin{tabular}{lc}
\hline Table 1. The Characteristics of Study Patients & \\
\hline Variable & Median (Range) \\
\hline Age, $\mathbf{y}$ & $48.3(25-84)$ \\
Duration, mo & $4.5(1-12)$ \\
Severity, Ikeda & $4.1(2-8)$ \\
\hline
\end{tabular}

scores in subscales (Table 2). No significant association was found between age, sex, type of skin or mucosal involvement, duration of disease, marriage status, and GHQ28 score. Considering the severity score of the disease, all healthy patients in GHQ-28 score had mild severity $(\mathrm{P}<$ 0.05). There was a reverse relationship between disease severity and GHQ-28 values $(\mathrm{P}<0.05)$ (Table 3 ).

\begin{tabular}{lccc}
\hline Table 2. The GHQ-28 and Its Subscales of the Study Population \\
\hline & \multicolumn{3}{c}{ Severity } \\
\cline { 2 - 4 } & $\begin{array}{c}\text { Negative or } \\
\text { Healthy }\end{array}$ & Mild & $\begin{array}{c}\text { Moderate to } \\
\text { Severe }\end{array}$ \\
\hline GHQ-28 & $<7$ & $7-11$ & $>11$ \\
\hline $\begin{array}{l}\text { Somatic } \\
\text { symptoms }\end{array}$ & 19 & 10 & 6 \\
\hline $\begin{array}{l}\text { Anxiety/insomnia } \\
\text { Social dysfunction }\end{array}$ & 12 & 18 & 5 \\
\hline Severe depression & 11 & 18 & 6 \\
\hline
\end{tabular}

\begin{tabular}{|c|c|c|}
\hline Variable & No. $(\%)$ & GHQ-28 Percent $\geq 23$ \\
\hline \multicolumn{3}{|l|}{ Gender } \\
\hline Male & $19(54.3)$ & 63.2 \\
\hline Female & $16(45.7)$ & 168.8 \\
\hline \multicolumn{3}{|l|}{ Severity (Ikeda) } \\
\hline Mild & $26(74.3)$ & 53.8 \\
\hline Moderate/severe & $9(25.7)$ & $100^{\mathrm{a}}$ \\
\hline \multicolumn{3}{|l|}{ Marriage status } \\
\hline Married & $23(65.7)$ & 60.9 \\
\hline Single/widow & $12(34.3)$ & 75 \\
\hline \multicolumn{3}{|c|}{ Mucocutaneous involvement } \\
\hline Both of them & $26(74.3)$ & 69.2 \\
\hline One of them alone & $9(25.7)$ & 55.5 \\
\hline
\end{tabular}

${ }^{\mathrm{a}} \mathrm{P}<0.05$

\section{Discussion}

Pemphigus is a rare chronic blistering skin disease that few studies have investigated general health status of pa- 
tients with this disease.

This study showed a negative effect of pemphigus on general health status of the patients. This finding is consistent with other previous studies (2-8). An interesting finding in this study was that these patients were new cases with short duration of the disease; therefore, without any negative effect of immunosuppressive therapeutic regimens. Most of them had mild severity of illness; however, the impact of the disease on their health has been significant. Most skin diseases are not fatal, but cutaneous lesions, especially in the face area, due to their effect on the patient's appearance, can affect the quality of life of patients and even occupational status (17). Awareness of this issue andproper control of these problems besides the main treatment regimens can help improve the patient's condition.

Many studies showed the differences between sex and general health status of the patients, and women were affected more than men (6), but others did not show this association $(3,4,18)$. In this study, the results cannot be generalized as sample size was small. Unfortunately, all patients had pemphigus vulgaris, and we had no other subtypes of this disease. Therefore, the association between the type of the disease and GHQ was not possible. In our study, there was an association between the severity score of disease with GHQ. It was consistent with other studies $(4,6-8,18)$. This study included patients with newly diagnosed non-treated pemphigus vulgaris. Although it may be a limitation of this study, the confounding factors such as side effects of drugs can be excluded. Change of health status over time is unexpected. Treatment of pemphigus can lead to complications that may affect the quality of general health. It seems that a recent diagnosis and limited access to information about the disease may influence the health status of patients, as the previous study also pointed out (8).

We had no control group, and we could not compare general health status of these patients with general population. Although the sample size in this study was small, all new known cases were entered during the study period. Finally, it is one of the few studies on the general health of these patients and can be used as basic information for future studies. The authors recommend that future studies should be carried out in other regions with a larger sample size, including all types of the disease.

1In conclusion, pemphigus had a significant negative impact on health status of 140 patients and should be considered in the treatment of the disease.

\section{Acknowledgments}

We thank the staff of the dermatology clinic of Razi hospital for their cooperation.

\section{Footnotes}

Authors' Contribution: Study concept and design: NA, AD, AG, AH. Literature search: AG, AH. Clinical studies: NA, $\mathrm{AD}, \mathrm{AH}$. Analysis and interpretation of data: AG. Drafting of the manuscript: NA, AD, AG, AH. Critical revision of the manuscript for important intellectual content: NA, A.D, AG. Statistical analysis: AG.

Conflict of Interests: The authors have no conflict of interest.

Ethical Approval: The ethical approval code was IR.GUMS.REC.1396.187.

Funding/Support: This research did not receive any specific grant from funding agencies in the public, private or not-for-profit sectors.

Informed Consent: Written informed consent was obtained from the patients.

\section{References}

1. Wojnarowska F, Venning VA. Immunobullous Diseases. Rook's Textbook of Dermatology. 2010. p. 1-62. doi: 10.1002/9781444317633.ch40.

2. Masahiro S, Shigaku I, Ogawa H. An investigation of quality of life (QOL) of pemphigus patients in Japan (First report). Jpn J Dermatol. 2000;110:283-8.

3. Terrab Z, Benchikhi H, Maaroufi A, Hassoune S, Amine M, Lakhdar H. [Quality of life and pemphigus]. Ann Dermatol Venereol. 2005;132(4):321-8. French. doi: 10.1016/s0151-9638(05)79276-0. [PubMed: 15886558].

4. Tabolli S, Mozzetta A, Antinone V, Alfani S, Cianchini G, Abeni D. The health impact of pemphigus vulgaris and pemphigus foliaceus assessed using the Medical Outcomes Study 36-item short form health survey questionnaire. Br J Dermatol. 2008;158(5):1029-34. doi: 10.1111/j.1365-2133.2008.08481.x. [PubMed: 18294312].

5. Paradisi A, Sampogna F, Di Pietro C, Cianchini G, Didona B, Ferri R, et al. Quality-of-life assessment in patients with pemphigus using a minimum set of evaluation tools. J Am Acad Dermatol. 2009;60(2):261-9. doi: 10.1016/j.jaad.2008.09.014. [PubMed: 19004524].

6. Paradisi A, Cianchini G, Lupi F, Di Pietro C, Sampogna F, Didona $B$, et al. Quality of life in patients with pemphigus receiving adjuvant therapy. Clin Exp Dermatol. 2012;37(6):626-30. doi: 10.1111/j.13652230.2011.04282.x. [PubMed: 22816985].

7. Ghodsi SZ, Chams-Davatchi C, Daneshpazhooh M, Valikhani M, Esmaili N. Quality of life and psychological status of patients with pemphigus vulgaris using Dermatology Life Quality Index and General Health Questionnaires. J Dermatol. 2012;39(2):141-4. doi: 10.1111/j.13468138.2011.01382.x. [PubMed: 21967321].

8. Tabolli S, Pagliarello C, Paradisi A, Cianchini G, Giannantoni P, Abeni D. Burden of disease during quiescent periods in patients with pemphigus. Br J Dermatol. 2014;170(5):1087-91. doi: 10.1111/bjd.12836. [PubMed: 24428431]. 
9. Urpe M, Pallanti S, Lotti T. Psychosomatic factors in dermatology. Dermatol Clin. 2005;23(4):601-8. doi: 10.1016/j.det.2005.05.021. [PubMed: 16112435].

10. Kumar V, Mattoo SK, Handa S. Psychiatric morbidity in pemphigus and psoriasis: a comparative study from India. Asian J Psychiatr. 2013;6(2):151-6. doi:10.1016/j.ajp.2012.10.005. [PubMed: 23466113].

11. 28-Item General Health Questionnaire. 2019, [cited 26 Aug 2019]. Available from: https://www.physio-pedia.com/28-Item_General_ Health_Questionnaire.

12. Sterling M. General Health Questionnaire - 28 (GHQ-28). J Physiother. 2011;57(4). doi: 10.1016/s1836-9553(11)70060-1.

13. Daniel BS, Hertl M, Werth VP, Eming R, Murrell DF. Severity score indexes for blistering diseases. Clin Dermatol. 2012;30(1):108-13. doi: 10.1016/j.clindermatol.2011.03.017. [PubMed: 22137234]. [PubMed Central: PMC3928011].

14. Nazifi M, Mokarami HR, Akbaritabar AK, Faraji Kujerdi M, Tabrizi R, Rahi A. Reliability, validity and factor structure of the persian transla- tion of general health questionnire (ghq-28) in hospitals of kerman university of medical sciences. J Fasa Univ Med Sci. 2014;3(4):336-42.

15. Taghavi SM. Reliability and Validity of General Health Questionnaire (GHQ). Psychology J. 2001;5.

16. Malakouti SK, Fatollahi P, Mirabzadeh A, Zandi T. Reliability, validity and factor structure of the GHQ-28 used among elderly Iranians. Int Psychogeriatr. 2007;19(4):623-34. doi: 10.1017/S1041610206004522. [PubMed: 17069666]

17. Wang EQ, Castrillón Velásquez M, Murrell DF. The effects of autoimmune blistering diseases on work productivity: A review. International Journal of Women's Dermatology. 2018;4(3):131-8. doi: 10.1016/j.ijwd.2017.11.001.

18. Sung JY, Roh MR, Kim SC. Quality of Life Assessment in Korean Patients with Pemphigus. Ann Dermatol. 2015;27(5):492-8. doi: 10.5021/ad.2015.27.5.492. [PubMed: 26512162]. [PubMed Central: PMC4622882]. 